\title{
A Study of Requests Made by Negative Politeness in English Movies and Their Persian Subtitles
}

\author{
Sahar Yaghoubzadeh \\ Faculty of Persian Literature and Foreign Languages, University of Tabriz, Tabriz, Iran
}

\begin{abstract}
Based on Brown \& Levinson's politeness theory (1987), this paper sought to explore the negative politeness sub-strategies in English and Persian requests by analyzing the Persian subtitles of each British and American movie consisting of Little Women (2019), The Man Who Knew Infinity (2015), Twilight (2008), and Twilight and the New Moon (2009). The aim was to define the frequency of applied sub-strategies in both languages and the cultural differences in applying them. In addition, Persian subtitles of requests were studied based on Newmark's translation procedures (1988) to both define the frequency of employed strategies and measure the precision of rendered utterances. Being fifty-one in bulk, all kinds of requests extracted from movies were analyzed. The study revealed that 'State the FTA as a general rule', 'Nominalize', and 'Go on record as incurring a debt' were absent in both languages. The highest and the lowest frequency of substrategies belonged to 'Question/Hedge' and 'Apologize' respectively. The frequency of each sub-strategy of 'Impersonalize S \& $\mathbf{H}$ ' and 'Give deference' was far higher in Persian from English. As to the translation, out of sixteen procedures, eleven of them were used. 'Literal Translation', 'Functional Equivalent', and 'Reduction' were the most frequently used strategies. Furthermore, subtitle of an utterance was rendered not according to the context in the movie.
\end{abstract}

Index Terms-Politeness Theory, Face Threatening Acts (FTAs), Negative Politeness Sub-Strategies, English requests, Persian requests, Newmark's translation procedures

\section{INTRODUCTION}

A converting process that helps people who speak different languages to understand each other's perspective and be able to maintain a healthy communication is translation. It gets down to connecting cultures and eradicating the cultural differences that might exist. The relationship between language, translation and culture is a key aspect of communication. Politeness is crucial to successful communication and is consequently of great interest to those who study language in its social context. (Sifianou, 1992) Along with Penelope Brown \& Stephen Levinson, there have been some other scholars who have developed theory or models of politeness including Robin. T Lakoff, Geoffrey Leech, Yueguo Gu, Sachiko Ide. (Leech, 2014) Nevertheless, politeness theory of the former has become more influential. Brown and Levinson categorized politeness strategies into four major types; on-record (direct), positive politeness, negative politeness, and off-record (indirect). They claimed that their model is universal; hence, there have been numerous challenges to this claim in different cultures and languages. The notion of 'face' proposed by Brown and Levinson is of two aspects of positive and negative. As maintained by Brown and Levinson (1987), "“face' is the public self-image that every member wants to claim for himself'. 'Negative face' is the want of every individual to not to be impeded by others and the 'positive face' is the want of every individual to be desirable to others. The acts intending to damage the face of the speaker and the hearer are called face-threatening acts (FTAs). Brown \& Levinson believe that while the content of face will differ in different cultures, the mutual knowledge of member's public self-image or face and the social necessity to orient oneself to it in interaction are universal. Requests are sort of face-threatening acts, so the speaker will impose on the hearer by requesting and consequently restrict the hearer's freedom of action thus, any rational speaker will apply established strategies to minimize the threat of the FTA. With increase in the indirectness of the FTAs, they sound more polite and minimize the imposition; thus, maintain the face of both the hearer and speaker.

Movies serve as a medium for both within-cultural and cross-cultural exchange of ideas and information. They attract people from all over the world through use of dubbing or subtitles to render the dialogs into another language. Politeness is the natural phenomenon amongst members of a community but it needs more considerable attention in cross-cultural communication. Every culture presents its own system of polite expression in the source language. Therefore, the translator should prepare the mutual situation in source and target language in order to convey the near sense of polite expressions. Considering the fact that languages and cultures are diverse, translators should be cognizant of the politeness aspect of languages, as well as other essential aspects, in rendering the SL into TL to minimize the imposition and threat to the face. Movies resemble a part of real life hence the requests made are near to the ones used in concrete context. For the present study, the selection of the requests were not restricted to specific ones rather all kinds of requests used in movies were analyzed. 
The objective of the current paper is to demonstrate the differences in English and Persian based on using the politeness strategies. The questions of the study were as follows:

1) How does the frequency of negative politeness sub-strategies in English requests change after being rendered into Persian?

2) Which translation strategies are considered most useful in rendering English requests regarding the aspect of negative politeness?

\section{REVIEW OF LITERATURE}

Since Brown and Levinson proposed their theory of politeness (1970s-1980s), great effort has been devoted to the study of politeness strategies in various languages and cultures. However, so far, a few researches on negative politeness strategies and their translation have been conducted regarding the Persian language. Several publications that have appeared about the different aspects of requests in diverse languages among the great deal of studies are thus: Cuban Spanish (Ružickova 1998), Hebrew and American English (Blum-Kulka 1987), Polish (Wierbzicka 2003), Greek and British English (Sifianou 1992), and Australian English, Canadian French, German, Hebrew, and Argentine Spanish (Blum-Kulka, House, \& Kasper 1989). Yaqubi \& Afghari's (2011) Cross-Cultural Study of Politeness Strategies Applied in Translations of English Requests as Face-Threatening Acts into Persian was one of the influential papers regarding the Persian language.

Yaqubi \& Afghari (2011), in their study, based on Brown and Levinson's model, examined the strategies of offrecord and negatives politeness applied to the requests taken out from seven American/British movies. Their objective was to discover the politeness sub-strategies applied in English and Persian to compare the two cultures along with examining translation strategies applied for translating English requests to Persian. Their instrument was consisting of one questionnaire involving thirty English requests applicable to off-record and negative politeness strategies. They had asked thirty Persian-speaking MA and PhD students of translation studies in University Sains Malaysia to translate them into Persian. Their outcome proved that the sub-strategy of 'be pessimistic' was added in Persian while it was missing in English. Furthermore, among the translation strategies of Newmark (1988), 'expansion' and 'literal translation' were the most frequently used procedures for rendering requests made by negative and off-record politeness strategies respectively.

Another paper by Moradi and Jabbari (2015) investigated the translation strategies used in translating negative politeness strategies based on Brown \& Levinson's politeness theory as well as their quality assessment (TQA). The study was done by analyzing the novel Grapes of Wrath and selecting randomly the utterances encompassing negative politeness strategies. Then the extracted data were analyzed based on Newmark's (1988) translation strategies, Rahimi's (2004) translation theory, and Zamani's (2013) TQA framework. The results of the research proved that the most frequently used translation strategies of expansion, literal translation, and functional equivalent can facilitate the translation process of negative politeness strategies. In addition, the quality of Persian translation was average, which means professional translators require the expertise of pragmatic aspects of language at a higher level. As to the highly frequent sub-strategies of negative politeness, the results were not the same as those of Yaqubi \& Afghari (2011).

Akbari (2002) sought to find out if patterns of politeness differ from one language to another by analyzing strategies of positive and negative politeness as well as off-record. To say the least, regarding the negative politeness, the research revealed that among the strategies the use of 'giving deference' and 'nominalizing' were more culture specific.

Other than aforementioned studies, Assadi (1980) and Beeman (1986, 1976) have studied the pragmatics of politeness in Persian.

\section{OBJECTIVES}

- To identify the most and least frequently used sub-strategies of negative politeness in requests both in English and Persian

- To compare the frequency of sub-strategies of negative politeness in English with Persian

- To know the cultural differences in applying the sub-strategies in requesting both in English and Persian

- To identify the mostly used translation procedures in subtitling the politeness sub-strategies

- To measure the accuracy of the Persian subtitles regarding the requests

\section{Methodology}

With respect to the research objectives as well as answering the research questions "How does the frequency of negative politeness sub-strategies in English requests change after being rendered into Persian?" and "Which translation strategies are considered most useful in rendering requests regarding the aspect of negative politeness?", four American and British movies were used as the research materials. The presence of lifelike conversations in the movies was the main reason for this choice. Movies resemble their culture; hence, the way people interact with each other in different contexts and cultures is illustrated. Furthermore, subtitling them into another language challenges the translators to convey the exact, clear, and accurate meaning to the target language; thus, movies and their subtitles are a way of 
representing the culture of speaking of various societies if the intended meanings are rendered carefully. The collected data consist of fifty-one English requests as well as their Persian subtitles extracted from the movies. Having searched a lot, only one type of Persian subtitle was found for each movie except for one in which the subtitles for requests were almost identical. Brown and Levinson's politeness theory (1987) along with Newmark's (1988) translation procedures provided the framework for the current research.

\section{MATERIALS}

Materials of the present study were composed of four American/British movies involving Little Women (2019), the Man Who Knew Infinity (2014), Twilight (2008), and Twilight and the New Moon (2009). As for the Persian translations, the subtitles of the movies were employed.

\section{PROCEDURES}

Since this study was limited only to the requests made by negative politeness based on Brown and Levinson's politeness theory, merely the related ones were extracted from the aforementioned movies. First, by using Brown \& Levinson's politeness (1987) the sub-strategies of negative politeness applied to the English requests were analyzed. After gathering the Persian subtitles of the selected requests, the applied sub-strategies were analyzed. For the next step, the translations of the requests were studied based on Newmark's (1988) translation procedures. Contributors to the analysis of both negative politeness sub-strategies and translation procedures were the research papers of Yaqubi \& Afghari (2011), moradi \& Jabbari (2015), and Daghoughi \& Hashemian (2016). Frequency and percentages of occurrence were determined after analyzing the sub-strategies applied in both requests and translation. As the final step, the strategies' percentages of occurrence were compared to each other.

\section{RESULTS AND DISCUSSION}

The following are some of the items out of fifty-one cases found and analyzed. Persian subtitle of each request is provided just below the utterance. Among ten sub-strategies of negative politeness, only seven sub-strategies were used both in English and Persian requests.

(1) (SL): Excuse me sir. Could you direct me to New Court?

(TL): 'bebakhshid ghorban mitunid man ro be New Court rahnemayi konid?'

\section{(a) Sub-strategies of negative politeness in both languages:}

(1) Apologize:

a. 'excuse me'

b. 'bebakhshid'

(2) Giving deference:
a. 'sir'
b. 'ghorban', 'mitunid', 'rahnemayi konid'

(3) Conventionally indirect:

a. 'could you direct me to New Court?'

b. 'mitunid man ro be New Court rahnemayi konid?'

(4) Question:
a. 'Could you direct me to New Court?
b. 'mitunid man ro be New Court rahnemayi konid?'

(5) Impersonalize $\mathrm{S}$ and $\mathrm{H}$
a. 'sir'
b. /ghorbam/

You' avoidance: /mitunid//rahnemayi konid/

\section{(b) Procedures of translation}

(1) Literal translation:

a. 'bebakhshid', 'mitunid man ro be', 'rahnemayi konid'

(2) Transference:
a. 'New Court'

(3) Cultural equivalence:
a. 'ghorban' 
(2) SL: I think it best if you leave.

TL: 'fekr konam behtar basheh ke shoma berin.'
(a) Sub-strategies of negative politeness in both languages:

(1) Hedges:
a. 'I think', 'if you leave'
b. 'fekr konam'

(2) Giving deference:
a. 'shoma berin'
(b) Procedures of translation:

(1) Literal translation:
a. 'fekr konam', 'shoma'

(2) Reduction:
a. 'if'

(3) Functional equivalence:
(a) 'berin', 'fek konam behtar bashe'

(3) SL: Could you use three more players?

TL: 'tuyeh timetun se ta jayeh khali nadarin?'
a. Sub-strategies of negative politeness in both languages:

(1) Being pessimistic:
a. 'could you'
b. 'jayeh khali nadarin'

(2) Conventionally indirect:
a. 'could you use three more players'

(3) Question:
a. 'Could you use three more players?'
b. 'Tuyeh timetun se ta jayeh khali nadarin ?'
(b) Procedures of translation:

(1) Literal translation:
a. 'se ta'

(2) Modulation:
a. 'tuye timetun se ta jaye khali nadarin?'

(3) Reduction:
a. 'could you use', 'more players'

(4) Expansion:
a. 'tuye timetun' 'jaye khali nadarin?'

(4) SL: But if it's not too much to ask, can you just promise me something?

TL: /amma agheh kheili chizeh ziyadi nist misheh haddeaghal yeh gholi behem bedi?/
(a) Sub-strategies of negative politeness in both languages:

(1) Question/Hedges:
a. 'but if it's not too much to ask', 'just', 'can you just promse me something?'
b. 'amma aghe kheili chize ziyadi nist', 'haddeaghal', 'mishe haddeagal ye gholi behem bedi?'

(2) Minimize the imposition:
a. 'just'
b. Haddeaghal'
(b) Procedures of translation: 
(1) Literal translation:

a. 'ama age kheili chize ziyadi nist', ' gholi behem bedi'

(2) Reduction:

a. 'to ask'

(3) Functional equivalence:

a. 'mishe', 'hadeaghal'

(5) SL: Jo, can you get more firewood?

TL: 'Jo, mituni beghardi hizomeh bishtari ghir biyari?'
(a) Sub-strategies of negative politeness in both languages:

(1) Question/hedge:
a. 'Can you get more firewood?'
b. ' mituni beghardi hizomeh bishtari ghir biyari?'
(b) Procedures of translation:

(1) Literal translation:
a. ' mituni', 'hizome bishtari'

(2) Functional equivalence:
a. 'ghir biyari'

(3) Expansion:
a. 'beghardi'

(4) Transference:
a. 'jo'

(6) SL: I would love to read what you're writing, if you'll trust me.

TL: 'kheili moshtagam dastani ke darid minevisid ro bekhunam, aghar be man etemad mikonid'
(a) Sub-strategies of negative politeness in both languages:

(1) Be pessimistic:

a. 'I would love'

(2) Hedges:
a. 'if you'll trust me'
b. 'aghar be man etemad mikonid.'

(3) Impersonalize $\mathrm{S}$ and $\mathrm{H}$ :
a. 'darid minevisid', 'be man etemad mikonid'
(b) Procedures of translation:

(1) Literal translation:
a. 'bekhunam', 'darid minevisid', 'agar be man etemad mikonid'

(2) Shift/ transposition:
a. 'etemad mikonid'

(3) Expansion:
a. 'dastani'

(4) Functional equivalence:

a. 'kheili moshtagham'

(5) Reduction:
a. 'Would' 
TABLE 1.

BROWN \& LEVINSON'S NEGATIVE POLITENESS SUB-STRATEGIES

\begin{tabular}{|c|c|c|c|c|}
\hline $\begin{array}{l}\text { Negative } \\
\text { Politeness } \\
\text { Sub-strategies }\end{array}$ & $\begin{array}{l}\text { Their } \\
\text { frequency } \\
\text { In English }\end{array}$ & $\begin{array}{l}\text { Their percentages } \\
\text { In SL }\end{array}$ & $\begin{array}{l}\text { Their } \\
\text { frequency } \\
\text { In Persian }\end{array}$ & $\begin{array}{l}\text { Their percentages } \\
\text { In TL }\end{array}$ \\
\hline 1.Be conventionally indirect & 44 & 25.73 & 40 & 20.72 \\
\hline 2. Question/ Hedge & 67 & 39.18 & 59 & 30.56 \\
\hline 3. Be pessimistic & 25 & 14.61 & 30 & 15.54 \\
\hline 4. Minimize the imposition, $\mathrm{Rx}$ & 9 & 5.26 & 8 & 4.14 \\
\hline 5. Give deference & 8 & 4.67 & 23 & 11.91 \\
\hline 6. Apologize & 2 & 1.16 & 2 & 1.03 \\
\hline 7. Impersonalize $\mathrm{S}$ and $\mathrm{H}$ & 16 & 9.35 & 31 & 16.06 \\
\hline 8. State the FTA as a general rule & 0 & 0 & 0 & 0 \\
\hline 9. Nominalize & 0 & 0 & 0 & 0 \\
\hline $\begin{array}{l}\text { 10.Go on record as incurring a debt, } \\
\text { or as not indebting }\end{array}$ & 0 & 0 & 0 & 0 \\
\hline Total & 171 & $100 \%$ & 193 & $100 \%$ \\
\hline
\end{tabular}

As the Table 1 shows, 'State the FTA as a general rule', 'Nominalize', and 'Go on record as incurring a debt' were absent in both languages. The highest and the lowest frequency of sub-strategies were of 'Question/Hedge' and 'Apologize' respectively. The percentages of sub-strategies 'Be Pessimistic', 'Give deference', and 'Impersonalize S \& H' were increased in TL, whereas the percentages of the sub-strategies 'Be conventionally indirect', 'Question/Hedge', 'minimize the imposition', and 'Apologize' were decreased. The frequency of sub-strategies used in both languages is all but near to each other except for 'Give Deference' and 'Impersonalize S \& H', which are different with each other by a relatively larger margin.

In example (2), two hedges are used in the SL: / I think/ /if you leave/ which are normally used in negative politeness, however, after rendering into Persian, only one of the hedges is used, so by the omission of 'if clause hedge' the sentence has been altered into on-record strategy (shoma berin).

The example illustrated below is a request for permission in which (Do you mind if...?) is used as conventional indirectness, however it is stated differently in Persian (mitunam...?) that is equivalent with 'Can I?' in English. Nevertheless, despite the different forms of expression and meaning, both of them are conventionally indirect.

TL: Do you mind if I look?

SL: 'Mitunam neghah konam?'

The current findings contradicted the results of Yaghoubi \& Afghari's research paper especially the one most sharply different was the sub-strategy 'impersonalize S \& H'. Considering Brown \& Levinson's points for the sub-strategy 'impersonalize' like: "Address terms as 'you' and 'I' avoidance"”, "Pluralization of the 'you' and 'I' pronouns, and "Point-of-view distancing", sub-strategy of 'Impersonalize S \& H' was one of the most frequently used sub-strategies.

Point-of-view distancing example: I was just wondering if you wanted to go see a movie with me.

In Persian like French and some other languages, there are two ways of redressing the hearer; singular pronoun and plural pronoun. Therefore, the use of plural pronoun 'shoma' in Persian is both considered as 'Give deference' and 'Impersonalize hearer'.

In the following example, the omission of the pronoun (shoma) in Persian and pluralization of the verb (mibakhshid) leads to the imporsanlization of the Hearer and the plularization of the verb in persian is a way of giving deference.

SL: Would you excuse me a second?

TL: 'Chand lahze mano mibakhshid?' 
TABLE 2.

NEWMARK's TRANSLATION PROCEDURES

\begin{tabular}{clll}
\hline Used Translation & Their frequency & Their percentage \\
Procedures & & 2.65 \\
\hline 1. & Transference & 6 & 0.88 \\
2. & naturalization & 2 & 2.65 \\
3. & Cultural equivalent & 6 & 16.81 \\
4. & Functional equivalent & 38 & 0.88 \\
5. & Descriptive equivalent & 2 & 6.19 \\
6. & Shifts/transposition & 14 & 6.19 \\
7. & modulation & 14 & 0.88 \\
8. & compensation & 2 & 40.70 \\
9. & Literal translation & 92 & 14.15 \\
10. & Reduction & 32 & 8 \\
11. & Expansion & 18 & $100 \%$ \\
\hline \hline Total & & 226 & \\
\hline
\end{tabular}

As Table 2 shows, the most frequently used procedure for subtitling the requests into persian was 'Literal translation'. This contradicted Yagoubi \& Afghari's paper in which 'Expansion' was the most used strategy for rendering requests made by negative politeness strategy. In this study, other than 'Literal translation', 'Functional equivalent' and 'Reduction' were the most preferred strategies.

In the following examples,

a. SL: Do you mind getting Dad?

TL: 'mishe baba ro sedash koni?'

b. SL: Can you pull in?

TL: 'mishe neghah dari?'

c. SL: Can I have the pass?

TL: 'mishe barghe vurudetun ro bedin be man?'

d. SL: You can't go another weekend?

TL: 'nemishe ye hafte ye dighe beri?'

'mishe...?' and 'nemishe...?' which are considered as 'Being Pessimist' in Persian, have been rendered by 'Functional Equivalent' procedure. In example (d), "weekend" is rendered to Persian meaning "week".

In some of the sentences as shown below, in Persian translation, there is a tendency to pluralize the speaker and the hearer in addressing the hearer. However, in English, only the addressee is addressed.

a. TL: All right, Miss Michelangelo, can you please rehearse the fainting scene?

SL: 'Khanume Michelangelo, mishe lotfan sahneye ghash kardan ro tamrin konim?'

b. TL: Major, can I have a word?

SL: 'Sarghord, mitunim sohbat konim?'

c. TL: Mom, can I talk to you later?

SL: 'Maman, mishe baadan ba ham sohbat konim?'

d. TL: Do you want to go to Prom with me?

SL: 'Mikhay ba ham berim majlese raghs? Ba man?'

In addition, some cultural differences are illustrated in the following example;

a. But I intend to go to Europe one more time, and I need a companion, so how would you like to be the person I take?

/Vali mikham ye bare digheh beram Urupa va be ye hamrah niyaz daram. Dust dari to ro ba khodam bebaram?/

"Would you like to be the person I take?" is rendered as "Dust dari to ro ba khodam bebaram?" as a result of cultural factor.

Finally, yet importantly, the translation of some utterances was not correct and they were conveying totally a different message than it was intended in the source language as though they were not translated according to the context in the movie. In the case of requests, the utterance below was rendered incorrectly;

a. SL: Can you keep your thoughts to yourself?

TL: 'mituni darmoredeh khodetam pishbini koni?'

This, according to the context, should have meant 'Don't reveal your thoughts'.

\section{CONCLUSION}

The main aim of translation is to enrich the target language, both linguistically and culturally. Although, the tendency to maintain the face of the speaker and hearer is universal, some language and cultural particulars lead to the differences in using the speech acts. With respect to the first question, frequency of sub-strategies of 'Be conventionally indirect', 'Question/Hedge', and 'Minimize the imposition' were decreased in Persian. The frequency of 'Be pessimistic', 'Give deference', and 'Impersonalize S \& H' were increased in Persian. Additionally, the frequency of 'Apologize' was the same in both languages. Moreover, the three sub-strategies of 'state the FTA as a general rule', 'Nominalize', and 'Go 
on record as incurring a debt' were absent in both languages. Regarding the second question, among the sixteen procedures of translation proposed by Newmark (1988), eleven of them were used in subtitling. The most practical and frequently used strategies were 'Literal translation', 'Functional equivalent', and 'Reduction'. Furthermore, it has been demonstrated that if a sub-strategy has not been rendered precisely, it can lead to the alteration of the applied strategy in the target language. Further, in the subtitles that have been rendered not according to the context in a movie, there is a strong probability that a different possible message is conveyed instead. Overall, by the results of the study it was concluded that most of the preferences to make requests in both languages were in the result of the cultural particulars and it did not depend much on the universality.

\section{REFERENCES}

[1] Akbari, Z. (2002). The realization of politeness principles in Persian. Karen's Linguistics Issues, 12, 120-135

[2] Assadi, R. (1980). Deference: Persian style. Anthropological Linguistic, 22.5, 221-224.

[3] Beeman, W. (1976). Status, style and strategy in Iranian interaction. Anthropological Linguistic, 18.7, 305-322.

[4] Beeman, W. (1986). Language, status, and power in Iran. Bloomington: Indiana University press.

[5] Bhasha, B. (2018). Translation Agency. Understanding the Relationship between Translation and Culture https://medium.com/ (accessed 21/10/2020).

[6] Blum-Kulka, Sh. (1987). Indirectness and politeness in requests: Same or different? Journal of Pragmatics, 11.2, 131-146.

[7] Blum-Kulka, Sh., House, J., \& Kasper, G. (1989). Cross-cultural pragmatics: Requests and apologies. Norwood, N.J: Advances in discourse processes, Ablex, 31, 155-173

[8] Brown, P., \& Levinson, S. (1987). Politeness: Some universals in language usage. Cambridge: Cambridge University Press.

[9] Daghoughi, Sh., Hashemian, M. (2016). Analysis of Culture-Specific Items and Translation Strategies Applied in Translating Jalal Al-Ahmad's by the Pen. English language teaching, 9.4, 171-185.

[10] Leech, G. (2014). The pragmatics of politeness. Oxford: Oxford University Press.

[11] Moradi, N., \& Jabbari, M. (2015). Translation of Negative Politeness Strategies from English into Persian: The Case of Novel Translation International. Journal of Applied Linguistics \& English Literature, 4.2, 143-159.

[12] Newmark, P. (1988). A textbook of translation. England: Prince Hall International.

[13] Ružicková, E. (1998). Face, face-threatening acts and politeness in Cuban Spanish: University of Pittsburgh.

[14] Sifianou, M. (1992). Politeness phenomena in England and Greece: A cross-cultural perspective. Oxford, UK: Longman.

[15] Wierzbicka, A. (2003). Cross-cultural pragmatics: The semantics of human interaction (2nded.). Berlin: Mouton de Gruyter.

[16] Yaqubi, M., \& Afghari, A. (2011). A Cross-cultural Study of Politeness Strategies Applied in Translations of English Requests as Face-threatening Acts into Persian. Modern Journal of Language Teaching Methods, Dec. 2011, 31-44.

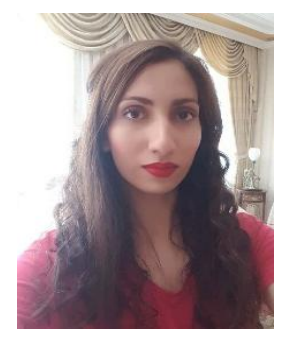

Sahar Yaghoubzadeh was born in Tabriz, Iran on 31 Dec.1998. She graduated from Iran language institute (ILI) in 2016. Currently, she is a senior student at the University of Tabriz, Iran and she will receive her BA in English language and literature in 2021.

She has been teaching English since 2019 and currently she is an English Teacher at Zabansara-e-Tabriz institute. Her areas of interest include pragmatics, language and culture, morphology, syntax, and semantics. 